\title{
Investigating the effect of Electronic Word Of Mouth on customer's purchase intention of digital products
}

\author{
Shabnam Khosravani Zangeneh ${ }^{\mathrm{a}^{*}}$, Reza Mohammadkazemi ${ }^{\mathrm{b}}$ and Mehran Rezvani ${ }^{\mathrm{b}}$
}

${ }^{a}$ Masters student, Faculty of Entrepreneurship, University of Tehran, Tehran, Iran

${ }^{b}$ Assistant. Prof. \& Faculty Member, Faculty of Entrepreneurship, University of Tehran, Tehran, Iran

\section{H R O N I C L E}

\section{Article history:}

Received June 4, 2014

Accepted 8 October 2014

Available online

October 102014

Word of mouth

Purchasing intention

Digital product

Product complexity

\section{A B S T R A C T}

This paper presents an empirical investigation to examine the effect of electronic word of mouth (eWOM) on purchasing intention. The study also considers the effects of quality of eWOM, quantity of eWOM as well as reviewers' expertise on purchasing intention. The study has accomplished among 384 people who have some experiences on buying digital devices from an Iranian well-known providers of electronic devices in city of Tehran, Iran. Using structural equation modeling, the study confirms the effects of eWOM on purchase intention. In addition, the study confirms the effects of quality of eWOM as well as reviewer's expertise on purchase intention. Moreover, the study examines the effects of two moderator variables, brand image and product complexity, on purchase intention and while the effect of brand image on purchase intention is confirmed but the impact of complexity on purchase intention is not confirmed.

\section{Introduction}

Word of mouth (WOM) (Bansal \& Voyer, 2000; Godes \& Mayzlin, 2004) has been one of the extensive methods for product development and there are literally many studies on learning more about the effects of various factors on marketing planning (Cakim, 2009). Bone (1995) investigated the effect of WOM communications on product judgments. In addition, he studied the moderating effect of several situational, personal, and source characteristics in three different experiments. The study indicated that WOM impacts on short-term and long-term judgments. This effect stated to be bigger when a consumer faces a disconfirmation experience and when an expert monitors the WOM communication. Brown et al. (2007) reported the results of a two-stage study aimed at studying online WOM where a set of in-depth qualitative interviews followed by a social network analysis of a single online community. Combined, the results provided some evidence that individuals may behave as if Web sites themselves were primary "actors" in online social networks and that online communities could act as a social proxy for individual identification. They offered a conceptualization of online social networks, which could take the Web site into account as an actor,

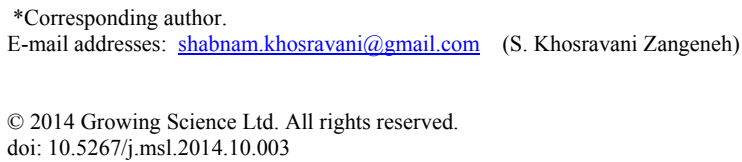


an initial exploration of the concept of a consumer-website relationship, and a conceptual framework of the online interaction and information evaluation process.

According to Chatterjee (2001) in a survey reported that the extent of WOM search depends on the consumer's reasons for selecting an online retailer. In addition, the impact of negative WOM information on perceived reliability of retailer and purchase intentions was determined largely by familiarity with the retailer and differed based on whether the retailer was a pure-Internet or clicksand-mortar firm. Chevalier and Mayzlin (2006) examined the effect of consumer reviews on relative sales of books at Amazon.com and Barnesandnoble.com. They reported that reviews were overwhelmingly positive at both sites, but there were more reviews and longer reviews at the first website. In addition, in this survey, an improvement in a book's reviews could lead to an increase in relative sales at that site. In addition, the effect of one-star reviews appeared to be bigger than the effect of five-star reviews and finally, the evidence from review-length data implied that customers could read review text rather than relying only on summary statistics.

Davis and Khazanchi (2008) investigated the effect of online WOM attributes and other related factors on e-commerce sales on a multi-product retail e-commerce firm. They reported that the introduction of online WOM on a retail e-commerce site could positively influence on product sales. They proposed and validated a conceptual model of online WOM and its effect on product sales and the effect of moderator variables such as promotion, product category and product views. In their survey, pure increase in volume or number of reviewer comments had no substantial impact on sales. According to Fan and Miao (2012), Electronic word of mouth (eWOM) (Brown \& Reingen, 1987; Gruen et al., 2006; Lin et al., 2013) is available to customers in various kinds of online consumer reviews used to help them make e-commerce purchasing decisions. Customers acknowledge that online consumer reviews could help them determine eWOM credibility and making purchasing decisions. This study used surveys and multiple regression analysis to generate an extended Elaboration Likelihood Model, which describes the relationship between customer expertise and involvement to acceptance and use of eWOM in making purchasing decisions. Hennig-Thurau et al. (2004) referred to e-WOM as any positive or negative statement (review) made by potential, actual, or former customers about a product or company, which is made available to a multitude of people and institutions via the internet. Similarly, Godes and Mayzlin (2004) defined eWOM that is measurable since comments on a product are written and available in the websites.

Jalilvand and Samiei (2012) investigated the effect of electronic word of mouth on brand image and purchase intention in in the automobile industry in Iran. Kalwani and Silk (1982) reported some further analyses and applications of Morrison's model of the predictive relationship between measures of intentions and subsequent purchasing behavior. Wang and Yang (2010) studied the effect of brand credibility, composed of trustworthiness, expertise, and attractiveness, on consumers' brand purchase intention in emerging economies, concentrating on China's automobile industry. They proposed that brand awareness and brand image played a moderating role in this relationship. Their results also disclosed that brand credibility exerts a positive effect on consumers' brand purchase intention. Brand image and brand awareness in this study were detected to positively moderate the relationship between brand credibility and consumers' brand purchase intention. In their study, eWOM is viewed from three dimensions, including eWOM quality, eWOM quantity, as well as reviewers' expertise. Quality of eWOM refers to the persuasive strength of comments embedded in an informational message (Bhattacherjee, 2006). Consumer buying decision can be based on some criteria or requirement that meet their needs and to determined their willingness to buy it will be based on their perceived of quality of information they received (Cheung 2008).

\section{The proposed study}

This paper presents an empirical investigation to examine the effect of electronic word of mouth (eWOM) on purchasing intention. The study also considers the effects of quality of eWOM, quantity 
of eWOM as well as reviewers' expertise on purchasing intention. Fig. 1 demonstrates the proposed study, which has been adapted from an earlier study by Lin et al. (2013) by replacing product involvement with product complexity.

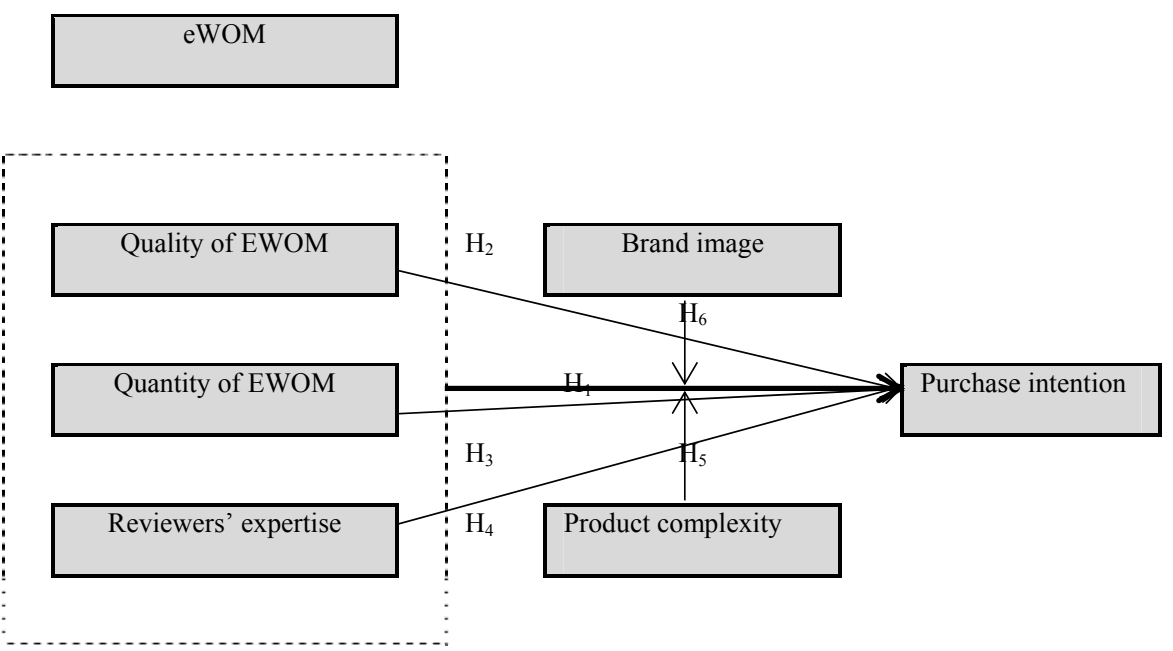

Fig. 1. The proposed study

According to Fig. 1, the following six hypotheses are proposed.

1. eWOM influences on purchase intention, positively.

2. Quality of eWOM influences on purchase intention, positively.

3. Quantity of eWOM influences on purchase intention, positively.

4. Reviewers' expertise influences on purchase intention, positively.

5. Product complexity is a moderator for the relationship between eWOM and purchase intention.

6. Brand image is a moderator for the relationship between eWOM and purchase intention.

This paper examines the hypotheses of this survey based on a survey accomplished among people who purchase different digital products from a supplier named digikala.com. The sample size is selected from the people, who live in city of Tehran, Iran as follows,

$N=Z_{\alpha / 2}^{2} \frac{p \times q}{e^{2}}$,

where $N$ is the sample size, $p=1-q$ represents the probability, $z_{\alpha / 2}$ is CDF of normal distribution and finally $\varepsilon$ is the error term. For our study we assume $p=0.5, z_{\alpha / 2}=1.96$ and $e=0.05$, the number of sample size is calculated as $N=384$. The study distributes 400 questionnaire and manages to collect 382 questionnaires filled, properly. There are three main variables on the proposed study including Quality f EWOM, Quantity of EWOM and Expert of a revewier. We first distribute the questionnaire designed in Likert among 30 professionals in order to vaidate the overal questionnaire. Cronbach alpha has been calculated as 0.917 , which is well above the minimum acceptable level. The study uses structural equation modeling to verify the components of the survey. Table 1 summarizes some basic statistics associated with all components of the survey and the results indicate that all components are within acceptance level.

\section{Table 1}

The summary of some basic statistics

\begin{tabular}{lccc}
\hline Variable & Extracted variance & VIF & Cronbach alpha \\
\hline Reviewers' expertise & 0.6058 & 0.8843 & 0.8358 \\
Brand image & 0.7207 & 0.9117 & 0.8709 \\
Purchase intention & 0.4639 & 0.8572 & 0.8057 \\
Product complexity & 0.5473 & 0.8787 & 0.835 \\
Quality of EWOM & 0.5977 & 0.8166 & 0.7027 \\
Quantity of EWOM & 0.5883 & 0.8935 & 0.8537 \\
\hline
\end{tabular}


Fig. 1 also summarizes personal characteristics of the participants. As we can observe from the results of Fig. 1, most participants were young single people with some university educations who work for some governmental as well as private organizations. In our survey, $44.5 \%$ of the participants prefer purchasing electronic devices because the process was simplified while $25.9 \%$ believed the site was reliable, $10 \%$ stated that the site offers reasonable prices and the $19.1 \%$ of the participants stated other reasons for purchasing electronic devices. Fig. 2 shows other related statistics on our survey. According to Fig. 2, most people purchase economic goods.

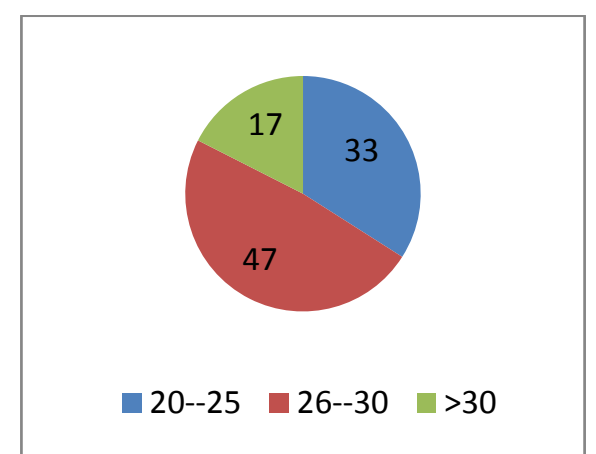

Age

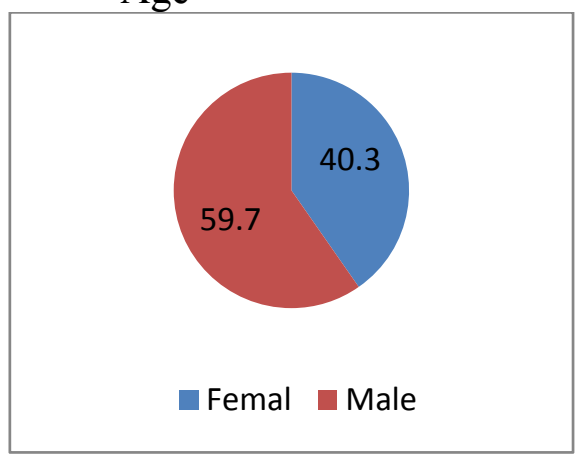

Gender

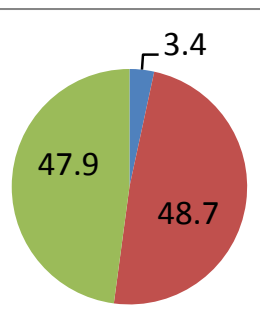

$\square 12 \square 16 \square 18$

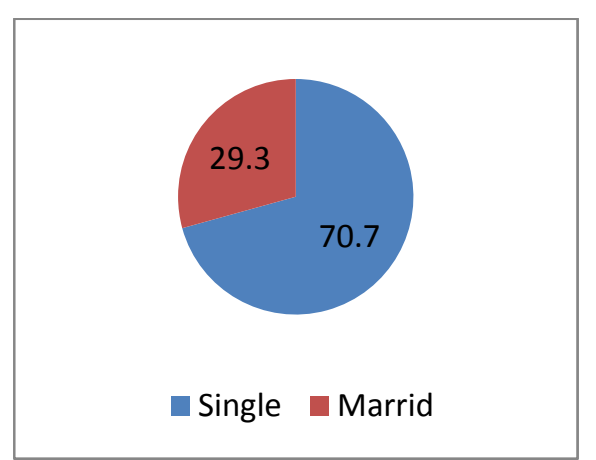

Marital states

Years of education

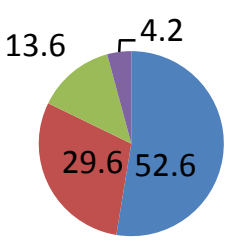

Regular employee $\square$ University student

Businessperson $\quad$ Unemployed

Employment status

Fig. 1. Personal characteristics of the participants

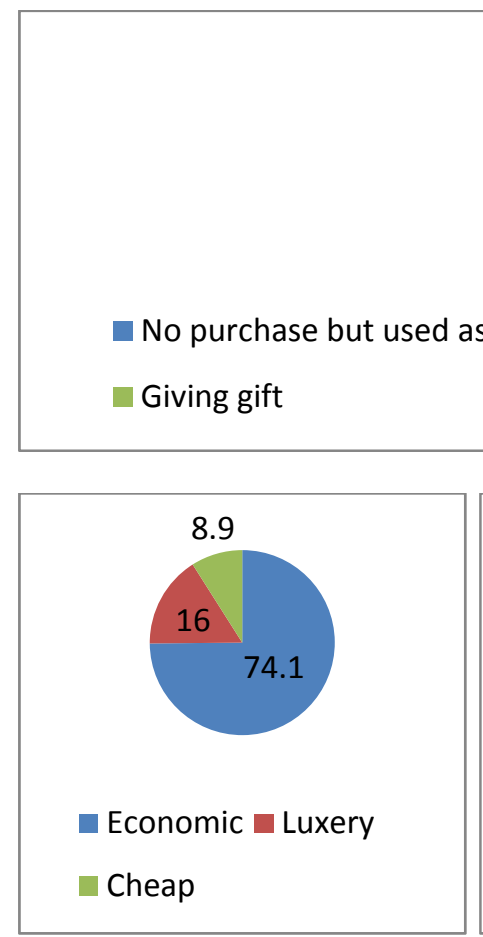

Type of products purchased

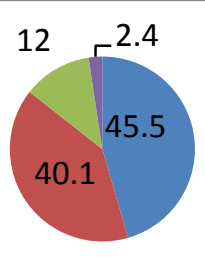

With some purchase motivation

Agent for firms

Motivation for purchase

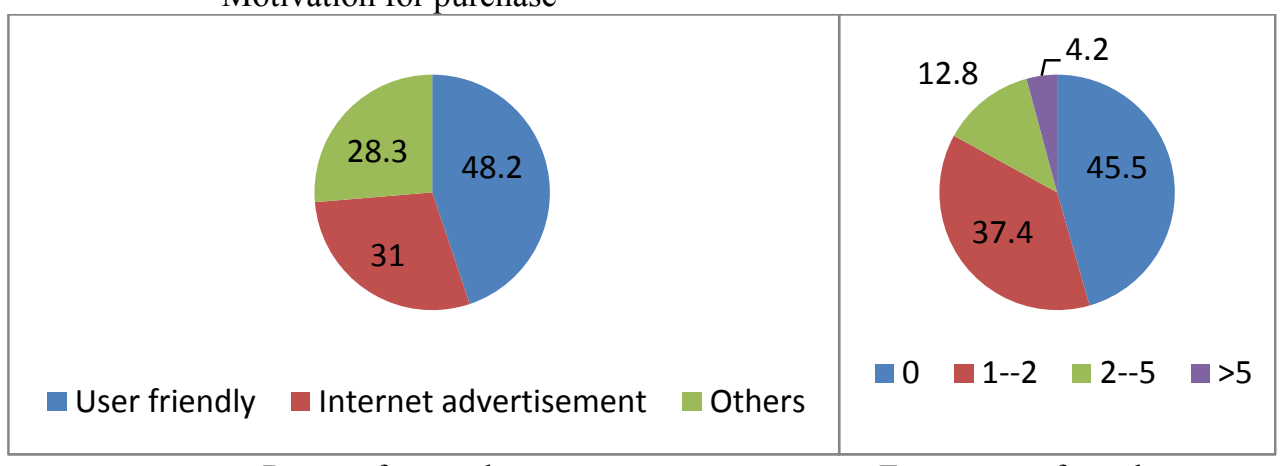

Reason for purchase

Frequency of purchases

Fig. 2. The reason for surfing/purchasing the website 


\section{The results}

In this section, we present details of our findings on testing various hypotheses of the survey.

\subsection{Examining the main hypothesis without the presence of moderator variables}

We first examine the main hypothesis of the survey without presence of moderator variables. Fig. 3 demonstrates the results of our survey.

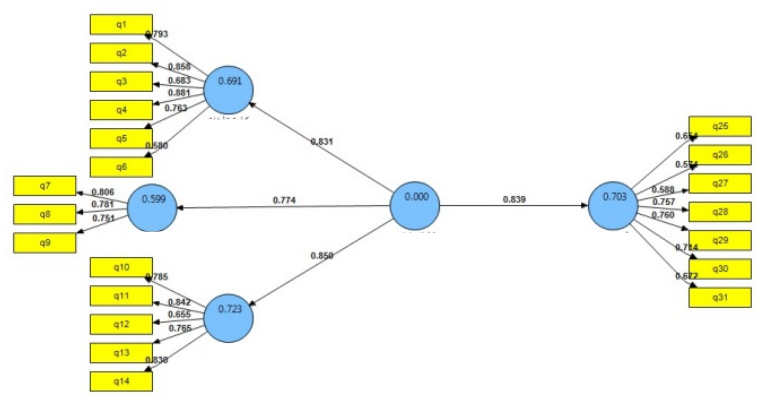

The results of standard coefficients

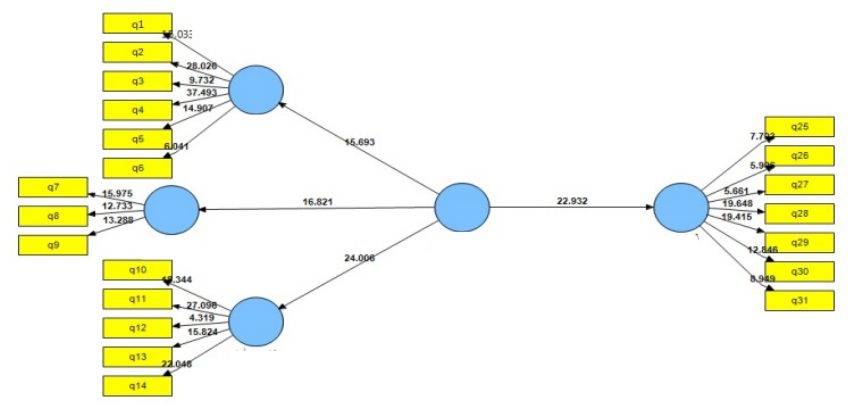

The results of t-student values

Fig. 3. The results of testing the main hypothesis without presence of moderator variables

The results of t-student values are all statistically meaningful when the level of significant is five percent. The positive coefficient between eWOM and purchase intention is equal to 0.839, which means there is a positive and meaningful relationship between these two variables. This confirms the main hypothesis of the survey. Next, we look at the sub-hypotheses of the survey using the moderator variable.

\subsection{Examining the sub-hypotheses without the presence of moderator variables}

We now examine all other sub-hypotheses of the survey without presence of moderator variables. Fig. 4 demonstrates the results of our survey.

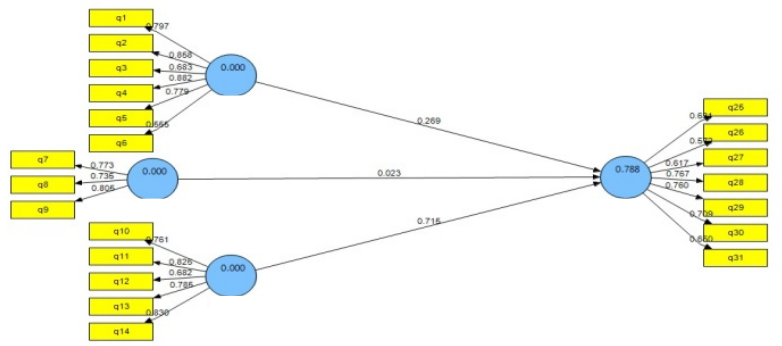

The results of standard coefficients

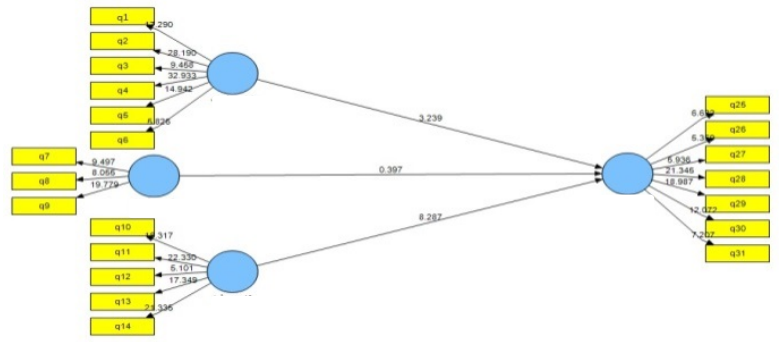

The results of t-student values

Fig. 4. The results of testing different hypotheses without presence of moderator variables

According to the results of Fig. 4, there is a meaningful and positive relationship between the quality of eWOM and purchasing intention $(\beta=0.269$, $\mathrm{t}$-value $=3.239$, Sig. $=0.001)$. In addition, there is a meaningful and positive relationship between reviewers' expertise and eWOM $(\beta=0.716$, t-value $=$ 0.397 , Sig. $=0.123$ ). However, there is not any meaningful relationship between quantity of EWOM and purchasing intention $(\beta=0.023$, t-value $=8.287$, Sig. $=0.001)$. 


\subsection{Examining the hypotheses with the presence of moderator variables}

Finally, we examine all other sub-hypotheses of the survey with the presence of moderator variables. Fig. 5 demonstrates the results of our survey.

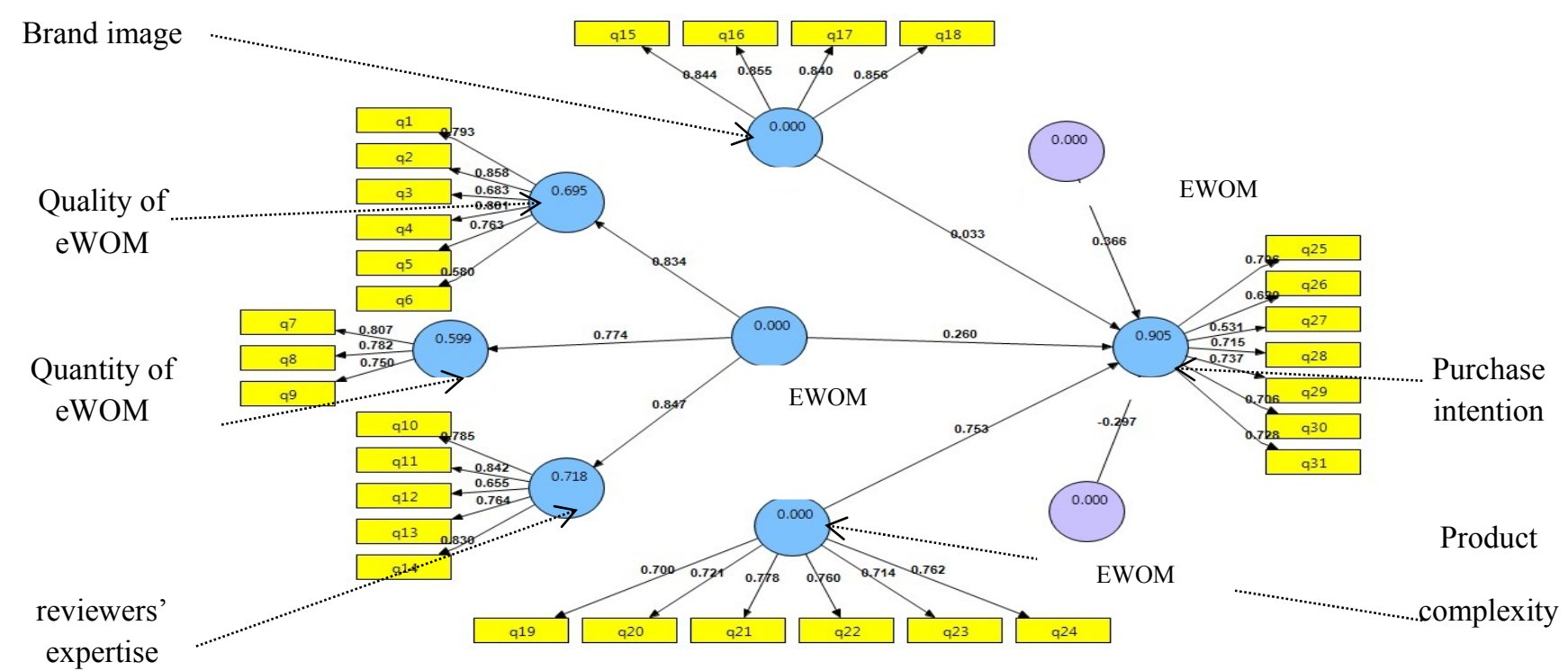

The results of standard coefficients

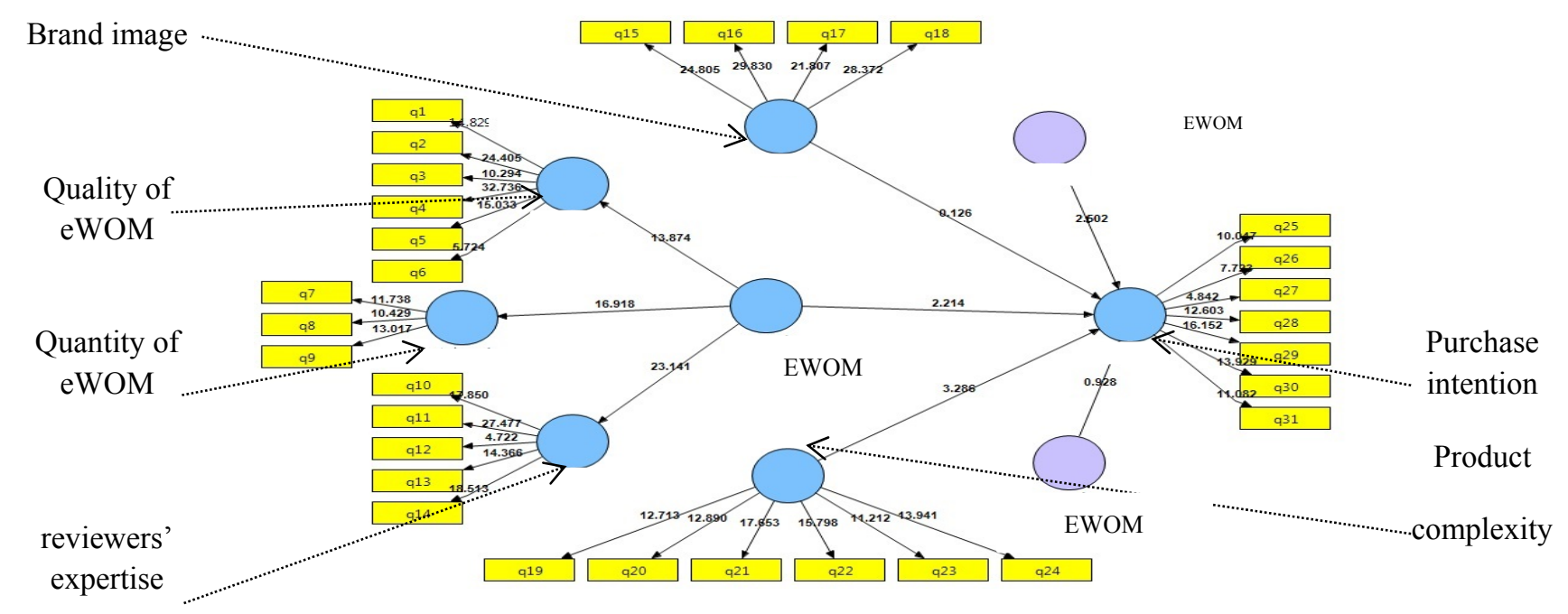

The results of $t$-value

Fig. 5. The result of structural equation modeling after adding the moderator variables

According to Fig. 5, brand image, as a moderator variable, influences positively on purchase intention $(\beta=0.366$, t-value $=2.602$, Sig. $=0.001)$ but product complexity does not have meaningful impact on purchase intention.

\section{Conclusion}

In this paper, we have presented an empirical investigation to examine the effect of electronic word of mouth on purchasing intention. Using structural equation modeling, the study confirmed the effects of eWOM on purchase intention. In addition, the study confirmed the effects of quality of eWOM as well as reviewer's expertise on purchase intention. Moreover, the study examined the effects of two 
moderator variables, brand image and product complexity, on purchase intention and while the effect of brand image on purchase intention was confirmed but the impact of complexity on purchase intention was not confirmed. The results of this study are somewhat consistent with findings stated by Lin et al. (2013). Table 2 summarizes the results of testing various hypotheses of the survey.

\section{Table 2}

The summary of testing six hypothesis of the survey

\begin{tabular}{llcc}
\hline Hypothesis & Relationship & $\beta$ & Result \\
\hline 1 & eWOM $\rightarrow$ purchase intention & 0.839 & Confirmed \\
2 & Quality of eWOM $\rightarrow$ purchase intention & 0.269 & Confirmed \\
3 & Quantity of eWOM $\rightarrow$ purchase intention & - & Not confirmed \\
4 & Reviewers' expertise $\rightarrow$ purchase intention & 0.716 & Confirmed \\
5 & Product complexity $\rightarrow$ purchase intention & - & Not confirmed \\
6 & Brand image $\rightarrow$ purchase intention & 0.366 & Confirmed \\
\hline
\end{tabular}

\section{Acknowledgement}

The authors would like to thank the anonymous referees for constructive comments on earlier version of this paper.

\section{References}

Bansal, H. S., \& Voyer, P. A. (2000). Word-of-mouth processes within a services purchase decision context. Journal of service research, 3(2), 166-177.

Bhattacherjee, A., \& Sanford, C. (2006). Influence processes for information technology acceptance: an elaboration likelihood model. MIS quarterly, 30(4), 805-825.

Bone, P. F. (1995). Word-of-mouth effects on short-term and long-term product judgments. Journal of Business Research, 32(3), 213-223.

Brown, J. J., \& Reingen, P. H. (1987). Social ties and word-of-mouth referral behavior. Journal of Consumer research, 14(3), 350-362.

Brown, J., Broderick, A. J., \& Lee, N. (2007). Word of mouth communication within online communities: Conceptualizing the online social network. Journal of Interactive Marketing, 21(3), $2-20$.

Cakim, I. M. (2009). Implementing word of mouth marketing: online strategies to identify influencers, craft stories, and draw customers. John Wiley \& Sons.

Chatterjee, P. (2001). Online reviews: do consumers use them?. Advances in consumer research, 28, 129-133.

Chevalier, J. A., \& Mayzlin, D. (2006). The effect of word of mouth on sales: Online book reviews. Journal of marketing research, 43(3), 345-354.

Cheung, C. M., Lee, M. K., \& Rabjohn, N. (2008). The impact of electronic word-of-mouth: The adoption of online opinions in online customer communities. Internet Research, 18(3), 229-247.

Davis, A., \& Khazanchi, D. (2008). An Empirical Study of Online Word of Mouth as a Predictor for Multi-product Category e-Commerce Sales. Electronic Markets, 18(2), 130-141.

Fan, Y. W., \& Miao, Y. F. (2012). Effect of electronic word-of-mouth on consumer purchase intention: The perspective of gender differences. International Journal of Electronic Business Management, 10(3), 175.

Godes, D., \& Mayzlin, D. (2004). Using online conversations to study word-of-mouth communication. Marketing Science, 23(4), 545-560.

Godes, D., \& Mayzlin, D. (2009). Firm-created word-of-mouth communication: Evidence from a field test. Marketing Science, 28(4), 721-739. 
Gruen, T. W., Osmonbekov, T., \& Czaplewski, A. J. (2006). eWOM: The impact of customer-tocustomer online know-how exchange on customer value and loyalty. Journal of Business research, 59(4), 449-456.

Hennig-Thurau, T., Gwinner, K. P., Walsh, G., \& Gremler, D. D. (2004). Electronic word-of-mouth via consumer-opinion platforms: What motivates consumers to articulate themselves on the Internet?. Journal of Interactive Marketing, 18(1), 38-52.

Jalilvand, M. R., \& Samiei, N. (2012). The effect of electronic word of mouth on brand image and purchase intention: An empirical study in the automobile industry in Iran. Marketing Intelligence \& Planning, 30(4), 460-476.

Kalwani, M. U., \& Silk, A. J. (1982). On the reliability and predictive validity of purchase intention measures. Marketing Science, 1(3), 243-286.

Kraus, S., Harms, R., \& Fink, M. (2010). Entrepreneurial marketing: moving beyond marketing in new ventures. International Journal of Entrepreneurship and Innovation Management, 11(1), 1934.

Lin, C., Wu, Y. S., \& Chen, J. C. V. (2013). Electronic Word-of-Mouth: The Moderating Roles of Product Involvement and Brand Image. In Diversity, Technology, and Innovation for Operational Competitiveness: Proceedings of the 2013 International Conference on Technology Innovation and Industrial Management (pp. S3_29-47). ToKnowPress.

Wang, X., \& Yang, Z. (2010). The effect of brand credibility on consumers' brand purchase intention in emerging economies: The moderating role of brand awareness and brand image. Journal of Global Marketing, 23(3), 177-188.

Xiao, B., \& Benbasat, I. (2007). E-commerce product recommendation agents: use, characteristics, and impact. Mis Quarterly, 31(1), 137-209. 